\title{
PINTANDO, ANALISANDO E BORDANDO ISOMETRIAS EM PONTO CRUZ
}

\author{
PAINTING, ANALYSING AND EMBROIDING ISOMETRIES ON CROSS-STITCH
}

\author{
Sandra Aparecida Fraga da Silva, Sabrine Costa Oliveira * \\ Instituto Federal do Espírito Santo $(*)$ \\ Email: sandrafraga7@gmail.com, binecosta@gmail.com
}

\begin{abstract}
Resumo
Este trabalho relata uma pesquisa de iniciação científica que estuda as transformações geométricas, em especial as isometrias, por meio dos bordados manuais de ponto cruz. A pesquisa foi desenvolvida com análise de material bibliográfico para desenvolvimento de apostila com atividades didáticas e aplicação de oficinas para alunos da licenciatura e professores de matemática. Pela quantidade de atividades que podem ser realizadas envolvendo isometrias e bordados em ponto cruz, consideramos essa proposta como uma alternativa para o ensino de geometria relacionado com a arte. Percebemos que os participantes das oficinas conseguiram ampliar suas visualizações e abordagens intuitivas sobre algumas isometrias quando direcionadas ao processo de investigação e produção artística de bordados em ponto cruz.
\end{abstract}

Palavras-chave: transformações geométricas, ponto cruz, geometria, isometrias

\begin{abstract}
This paper reports a survey of a scientific research that studies the geometric transformations, particularly isometries, through the hand embroidery cross stitch. The research was conducted with analysis of bibliographic material to developing booklet with educational activities and implementation of workshops for students and teachers of undergraduate mathematics. By the amount of activities that can be performed involving isometries and cross-stitch embroidery, we consider this proposal as an alternative to the teaching of geometry associated with art. We realized that workshop participants were able to broaden their views and approaches on some intuitive isometries when directed to research and artistic production of cross-stitch embroidery process.
\end{abstract}

Keywords: geometric transformations, embroidery cross stitch, geometry, isometries 


\section{INTRODUÇÃO}

O artigo busca apresentar alguns dados de um projeto de pesquisa que fez parte do Programa Institucional de Voluntários de Iniciação Científica - PIVIC - desenvolvido no curso de Licenciatura em Matemática do Instituto Federal do Espírito Santo - IFES Campus Vitória - no período de agosto de 2011 a junho de 2012. O plano de trabalho dessa iniciação científica teve como objetivo propor novas alternativas para o ensino das transformações geométricas utilizando como objeto de estudo os bordados manuais de ponto cruz.

As transformações geométricas no plano são conteúdos de geometria que envolve diferentes conhecimentos matemáticos. Abordamos algumas isometrias, que fazem parte das transformações geométricas no plano, que podem ser desenvolvidas em diferentes atividades geométricas em sala de aula. As isometrias estão presentes tanto na natureza como em diversos campos da atividade humana, podendo ser percebida na arte, na arquitetura, na moda, enfim, está presente no mundo e faz parte de nossa vida. Investigar essas isometrias contribui para a visualização, para a organização da estrutura do pensamento e para a construção do raciocínio geométrico.

Este trabalho refere-se a uma investigação que buscou associar a matemática e a arte. Apresentamos um olhar mais detalhado para a arte em bordados manuais, mais especificamente em ponto cruz. Notamos que a matemática está presente em diferentes bordados manuais de artesanatos, como o ponto cruz, o ponto cheio, a vagonite e outros. Escolhemos o ponto cruz para focalizar nossa pesquisa, visto que seria amplo para uma iniciação científica analisar os diferentes tipos de bordados. Percebemos que no Brasil, culturalmente, as pessoas têm algum tipo de conhecimento sobre diferentes bordados seja por prática manual ou por visualizarem esse tipo de arte em suas residências ou locais comuns. Porém, defendemos que dificilmente essas pessoas analisam quantos conceitos matemáticos existem nesses artesanatos.

De acordo com pesquisas, o ensino atual precisa ser trabalhado de maneira que faça sentido para o aluno, criando condições para que esse possa construir o seu próprio conhecimento. No caso da geometria, consideram que ela deve ser lecionada de forma dinâmica visando incentivar o aluno a identificar e construir padrões, a perceber e dominar diversos elementos e conceitos inerentes à geometria (NASSER et al., 2004). Acreditamos que uma maneira de atender a alguns desses tópicos é uma interação entre a arte e a matemática. 
A partir de investigações observamos que diferentes conceitos geométricos poderiam ser abordados em atividades envolvendo ponto cruz, tais como: regularidades, padrões, ângulos, figuras geométricas, simetrias, rotações e outras diferentes translações geométricas. No entanto, vimos uma ampla possibilidade de discussão de conceitos sobre as isometrias que, normalmente, não são contempladas adequadamente nos currículos da educação básica. Diante dessa possibilidade iniciamos essa pesquisa de iniciação científica sobre a geometria presente nos bordados de ponto cruz.

No presente artigo iniciamos com uma abordagem relacionando a geometria com a arte, evidenciando em especial as transformações geométricas. Depois apresentamos nossa metodologia de pesquisa, o desenvolvimento da mesma apontando alguns resultados obtidos com o estudo e terminamos com algumas considerações sobre essa abordagem. Para este trabalho selecionamos algumas investigações dos bordados manuais e apresentamos o desenvolvimento das atividades elaboradas em oficinas para professores e futuros professores. Nossos objetivos neste artigo são apresentar algumas atividades envolvendo isometrias e ponto cruz e analisar a aplicação dessas atividades na formação de professores.

\section{GEOMETRIA E ARTE}

Observamos em documentos oficiais como o PCN de matemática (BRASIL, 1997) e o Guia do livro didático de matemática - PNLD (BRASIL, 2010) - a aposta em um ensino baseado na interdisciplinaridade, como princípio pedagógico que estabelece conexões entre áreas de conhecimentos. Os mesmos recomendam que o ensino de geometria seja articulado com a arte.

A utilização de bordados manuais foi uma maneira encontrada por nós para relacionar a matemática com a arte. Esse estudo é importante tanto na criação da sensibilidade quanto para o desenvolvimento da visualização, da análise e do raciocínio geométrico. A identificação e o trabalho relacionando isometrias e artesanatos contribui para aprimorar o olhar do aluno para a matemática presente no mundo que o rodeia. Esse conhecimento da arte é valorizado pelos Parâmetros Curriculares Nacionais apontando vantagens em apresentar conteúdos ligados a arte 
aos alunos. Esse documento afirma que "um aluno que exercita continuamente sua imaginação estará habilitado a construir um texto, a desenvolver estratégias pessoais para resolver um problema matemático" (BRASIL, 1997, p.14). Dessa maneira, a arte proporciona a expansão do universo cultural dos indivíduos, abrindo espaço à participação social, mobilizando sentidos e capacidades como imaginação e observação.

Os processos de ensino e aprendizagem da matemática, por muitos anos e ainda hoje, estão ligados à repetição de exercícios e memorização de fórmulas, tarefas que para os alunos não faz sentido e nem relaciona ao mundo que se vive. Ao trazermos a arte para a sala de aula de matemática é possível transformar o ambiente escolar em um espaço de criação, prazer, construção de conhecimentos e de descobertas. E ainda, espera-se que os alunos

\begin{abstract}
além de desenvolver a intuição e a imaginação, matemática e arte são disciplinas fundamentais por muitas outras razões. Por exemplo, a matemática é uma área naturalmente propícia ao desenvolvimento e à manutenção de um diálogo permanente com a vida e com outras áreas do conhecimento (FAIGUELERNT; NUNES, 2006, p.15).
\end{abstract}

Visualizando dessa maneira, a abordagem relacionando a matemática e a arte se integra em diversos caminhos auxiliando o desenvolvimento do pensamento crítico, da autonomia intelectual, da sensibilidade e da criatividade. E ao unir o estudo da geometria à arte aperfeiçoam-se habilidades de percepção e de visualização dos conceitos geométricos (BISOGNIN; ROSSI, 2009). Segundo os Parâmetros Curriculares Nacionais precisamos relacionar o estudo da geometria com o mundo físico, com "obras de arte pinturas, desenhos, esculturas e artesanato, de modo que permita ao aluno estabelecer conexões entre a Matemática e outras áreas do conhecimento" (BRASIL, 1998, p.51). No nosso estudo, escolhemos um artesanato manual, os bordados em ponto cruz, que está presente no cotidiano dos brasileiros. Sabemos que há alguns anos atrás esses bordados eram mais comuns, porém, ainda hoje notamos que continua presente, ampliando a possibilidade de identificação e de visualização.

Dentre as diversas possibilidades de abordagens de conteúdos matemáticos identificados nos bordados manuais escolhemos as transformações geométricas para aprofundamento nessa iniciação científica. Segundo Veloso (2000) esse tema tem tido um percurso atribulado no ensino da matemática. Esse autor ressalta de atuações do Movimento da Matemática Moderna - MMM 
que ocorreu em meio ao século XX tentou organizar o estudo das geometrias associando-as com transformações geométricas. Porém, mesmo considerando que a intenção tenha sido positiva, Veloso (2000, p. 67) afirma que teve uma "concretização negativa", visto que as transformações geométricas tenham sido abordadas de maneira estritamente formal. Esse autor aponta que após os anos de 1990, sugeriu-se que para se superar o fracasso anterior iniciasse o estudo de transformações geométricas de maneira intuitiva somente no ensino básico. Entretanto, Veloso (2000) afirma que após essas tentativas as transformações desapareceram das abordagens em sala de aula. Segundo ele "é essencial retomar a intenção de dar às transformações geométricas o seu papel importante no ensino da geometria, num tratamento que tenha seu ponto de partida e desenvolva as intuições que os alunos já possuem e prossiga numa via lenta de formalização ao longo de toda escolaridade" (VELOSO, 2000, p. 67). Nosso estudo baseia-se na parte intuitiva e de visualização dessas transformações não nos aprofundando nesse estudo na formalização, pois nossa intenção era mostrar que num artesanato comum podemos encontrar geometria.

Os Parâmetros Curriculares Nacionais recomenda ainda que os conceitos e procedimentos em relação às transformações geométricas para área de Espaço e Forma no $3^{\circ}$ ciclo do ensino fundamental

deve destacar-se também nesse trabalho a importância das transformações geométricas (isometrias, homotetias), de modo que permita o desenvolvimento de habilidades de percepção espacial e como recurso para induzir de forma experimental a descoberta, por exemplo, das condições para que duas figuras sejam congruentes ou semelhantes (BRASIL, 1998, p.51).

Dentre as diferentes transformações geométricas no plano identificamos dois grupos que são mais comuns, as isometrias e as homotetias. Entendemos que "as isometrias têm por característica principal manter invariantes as medidas e, portanto, a forma da figura. Isto significa que se uma figura geométrica sofrer uma transformação do tipo isometria, as medidas dos comprimentos e ângulos que aparecem na figura serão mantidos" (NASSER; TINOCO, 2004, p. 5). Já as homotetias são transformações em figuras geométricas que podem ser consideradas ampliações ou reduções das iniciais, mantendo a mesma forma, porém não necessariamente a mesma medida. Nesse grupo de transformações está incluída as semelhanças entre figuras. Neste trabalho dedicamos atenção especial às isometrias. 
Diante do citado anteriormente, consideramos que o estudo das transformações geométricas no plano torna-se mais prazeroso se aliado as artes, pois permite que o aluno visualize propriedades e conceitos geométricos facilitando a compreensão de conteúdos de geometria. Como o estudo das isometrias é relativamente novo no currículo da educação básica, assim alunos e professores precisam iniciar estudos sobre esse assunto de modo intuitivo e simples a partir de explorações de atividades desde as séries iniciais (NASSER; TINOCO, 2004).

\section{METODOLOGIA}

Nossa pesquisa tem natureza qualitativa, pois estamos interessados em investigar as isometrias presentes nos bordados em ponto cruz e como podemos abordar em atividades didáticas esses conceitos geométricos. Apontamos que esse estudo teve um foco específico e por um período determinado da iniciação científica ocorrida entre agosto de 2011 e julho de 2012, conforme citado anteriormente. Ressaltamos que estamos dando continuidade a essa investigação com outra iniciação científica que termina em julho de 2013, ampliando essa pesquisa.

Apresentaremos neste artigo duas fases da pesquisa. Na primeira fase realizamos um levantamento dos diferentes bordados manuais que poderiam ser explorados e diante da grande variedade de opções optamos pelo ponto cruz por causa das inúmeras possibilidades de estudo de conceitos matemáticos. Em seguida, estabelecemos uma pesquisa bibliográfica sobre as transformações geométricas no plano com a leitura de livros que abordassem o assunto e fizesse ligações entre arte e matemática (NASSER; SANT'ANNA, 1997; FAINGUELERNT; NUNES, 2006). Aprofundamos os estudos teóricos sobre transformações geométricas para conhecer melhor esses conceitos matemáticos e identificar possibilidades para nosso trabalho com o ponto cruz (CATUNDA et al.,1988).

Após o estudo sobre as transformações geométricas, iniciamos uma pesquisa em diferentes revistas de ponto cruz a procura de bordados que continham algum dos conceitos que desejávamos abordar. Com essa investigação elaboramos fichas que continham atividades didáticas ordenadas com os graus de dificuldades que, normalmente, surgem quando o assunto é estudado. Essas atividades foram criadas com o auxílio do programa PC-Stitch, que é um software 
gratuito que permite criar gráficos em ponto cruz e nos auxiliou na criação e adaptação desses gráficos que foram utilizados na produção de atividades que foram aplicadas nas oficinas com licenciandos e com professores que ensinam matemática.

O material produzido foi organizado em fichas separadas por tipo de transformação geométrica e aplicado nos eventos o qual participamos e a um grupo de futuros docentes em Matemática do IFES /Campus Vitória que aceitaram participar dessa pesquisa. Essa foi a segunda fase da nossa investigação, aplicar as oficinas e analisar as produções e discussões realizadas durante sua aplicação sobre as isometrias abordadas. Nessa fase nossos sujeitos de pesquisa foram os participantes das diferentes oficinas.

As oficinas foram separadas em diferentes momentos por tipo de transformação geométrica para facilitar a didática de apresentação desse conteúdo. Realizamos atividades em folhas de atividades e em ponto cruz com modelos de bordados envolvendo um ou mais tipo de isometria no plano. Durante as oficinas registrávamos por fotos as produções dos participantes e no fim de cada oficina realizamos avaliação oral e escrita do processo de aprendizagem e da proposta abordada.

A aplicação das oficinas se deu em três momentos: no evento da Semana da Matemática no IFES Campus Vitória, que aconteceu no dia 17 de maio; no 3o Simpósio Internacional de Pesquisa e Educação Matemática nos dias 27 e 28 de junho e no dia 10 de julho, no Laboratório de Matemática do IFES - Campus Vitória. Todos esses momentos aconteceram no ano de 2012 e participaram das oficinas alunos da graduação e professores de matemática.

\section{DESENVOLVIMENTO E DISCUSSÃO DOS DADOS}

Conforme dito anteriormente, realizamos pesquisa bibliográfica sobre as transformações geométricas e sua ligação com a arte. Em seguida, escrevemos sobre as diferentes transformações, suas características, suas relações e suas propriedades evidenciando os conceitos matemáticos presentes no material estudado que poderiam ser abordados por nós nas atividades planejadas. Vamos realizar as análises apontando as atividades juntamente com a aplicação das mesmas nas oficinas. A seguir pontuamos algumas falas dos participantes durante a avaliação para ressaltarmos algumas percepções e discussões evidenciadas por essas pessoas sobre essas oficinas. 
As oficinas tinham duração de 4 horas e, por esse motivo, adaptamos as fichas, selecionamos algumas atividades mais relevantes para os participantes e criamos uma única apostila com todas as transformações geométricas. Iniciamos a oficina abordando os conceitos de simetria e reflexão indagando os participantes sobre as definições e perguntando alguns exemplos dessas transformações no nosso cotidiano. Logo depois, iniciamos algumas atividades que consistiam em traçar o eixo de simetria de figuras planas e analisar gráficos de ponto cruz se existia ou não eixos de simetria e, posteriormente, marcá-los. Notamos que essa atividade foi fácil e os participantes conseguiram identificar os eixos de simetria (fig. 1). Essas atividades iniciais corroboram com a ideia de Veloso (2000) quando aponta que devemos iniciar pela intuição dos alunos, no nosso caso, participantes, como ponto de partida.

Figura 1 - Atividade sobre eixo de simetria e resposta de participante.
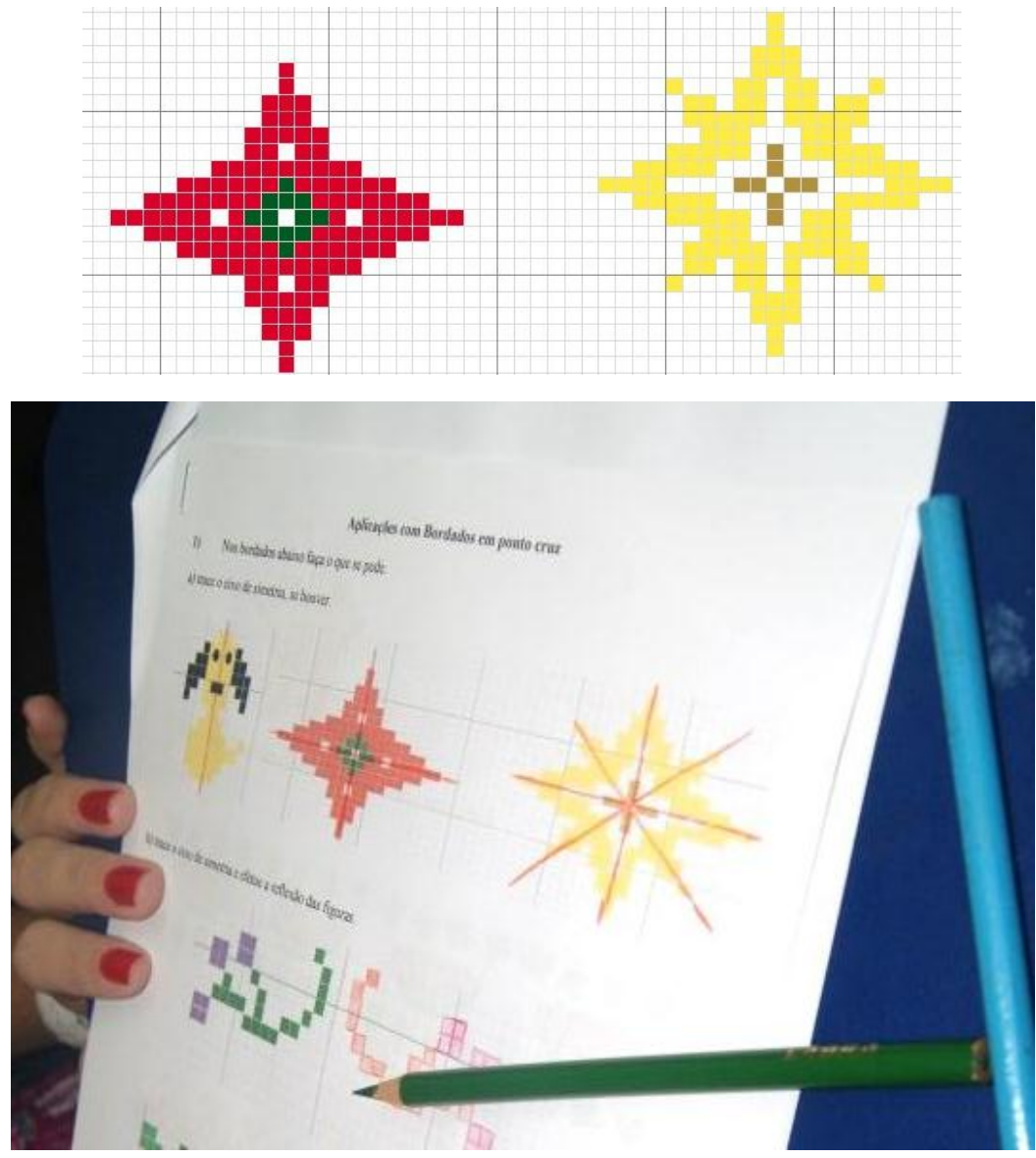

Fonte: Dados de pesquisa. 
Outra atividade abordada foi de reflexão a partir do traçado de um eixo de simetria, percebemos que a maioria dos participantes desenhou um eixo na vertical e efetuou a reflexão (fig. 2). Porém, tivemos uma participante que traçou o eixo de simetria na horizontal, ela conseguiu realizar a reflexão, mas visualmente não ficou tão nítido como nas demais apresentações das soluções (fig. 3). Essa atitude fez com que ela repensasse sua estratégia e tentasse fazer como os demais participantes.

Figura 2 - Atividade explorando simetria de reflexão.
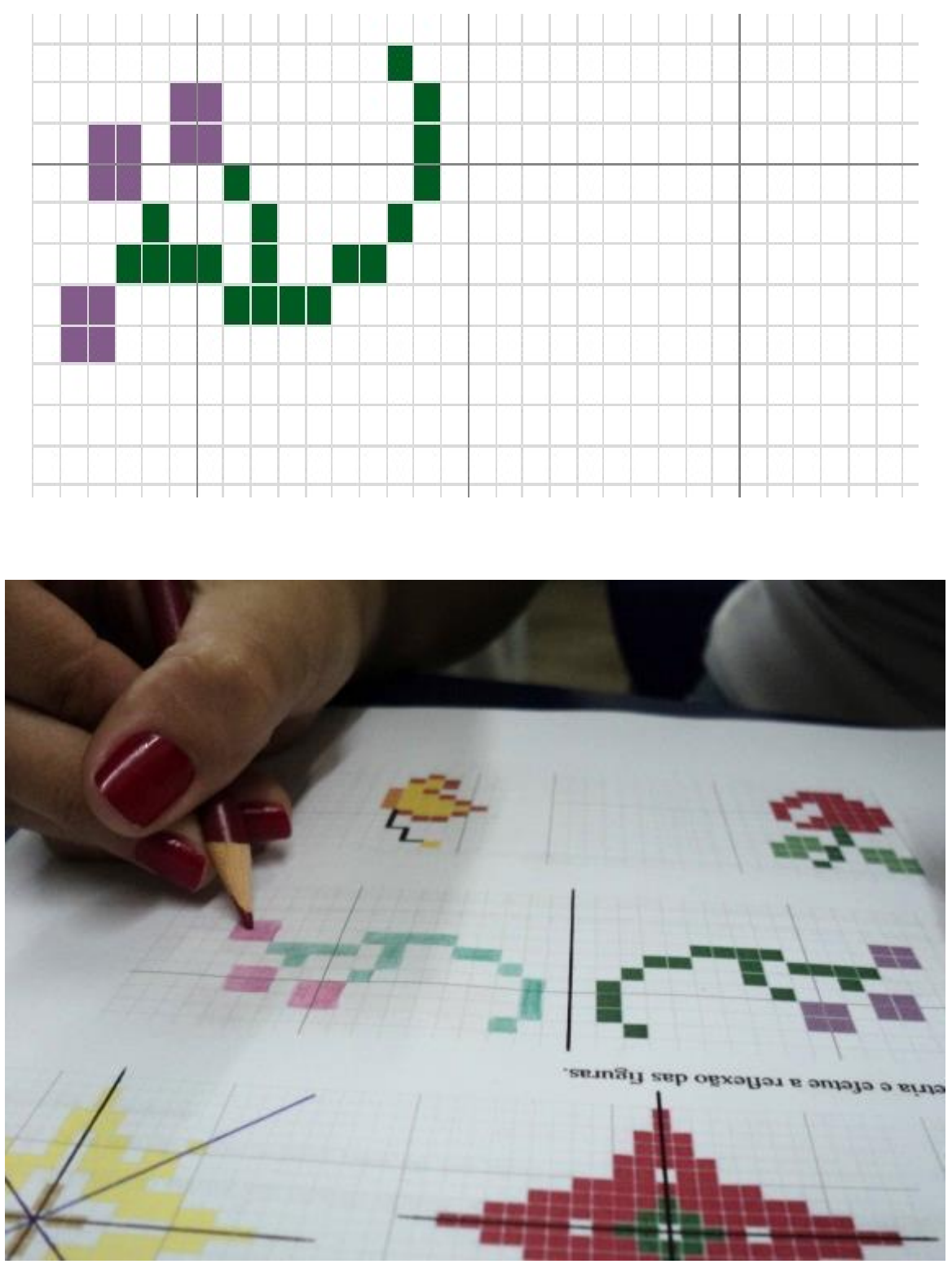

Fonte: Dados de pesquisa. 
Figura 3 - Atividade de simetria de reflexão com eixo horizontal.

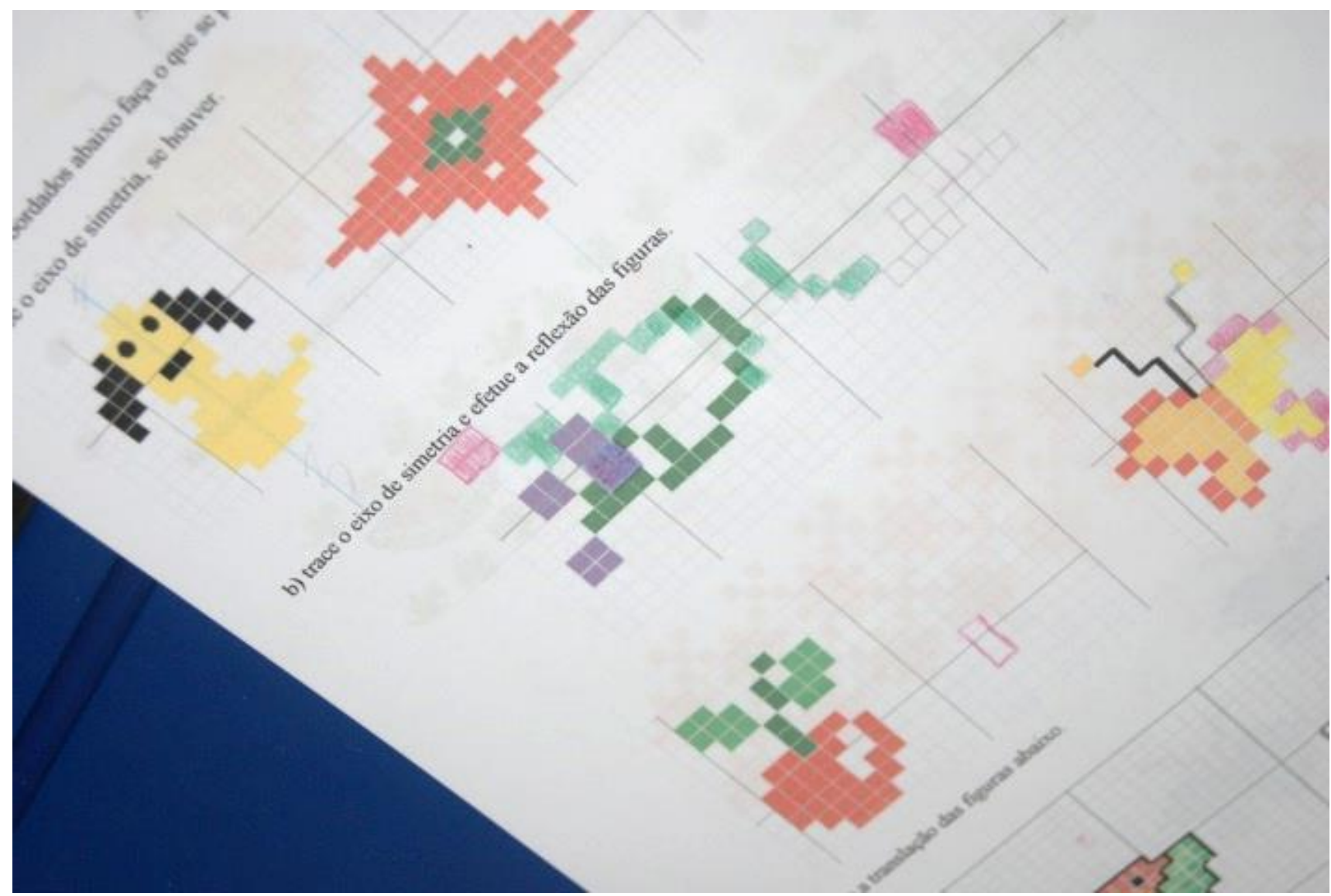

Fonte: Dados de pesquisa.

Em seguida, prosseguimos a oficina trabalhando os conceitos de translação e rotação, com atividades para completar o gráfico com a transformação geométrica pintando com lápis de cor e depois aplicávamos as transformações geométricas nos bordados manualmente. A figura 4 apresenta situações nas quais os participantes realizam as translações e identificam como as imagens estão sendo transladadas, foi interessante verificar as diferentes estratégias para a realização da translação. Algumas faziam o contorno da figura para iniciar a pintura, outras contavam os quadradinhos e escolhiam uma cor específica para iniciar o processo. Discutimos com eles como realizaram as questões, algumas diziam que eram como realizavam o ponto cruz nos bordados, contando os pontos. Esse processo de discussão do procedimento adotado é defendido por Nasser e Tinoco (2004) quando afirmam que devemos incentivar a argumentação para defender ideias utilizadas nas resoluções de atividades envolvendo transformações geométricas. 
Figura 4 - Atividade envolvendo translação de figuras.
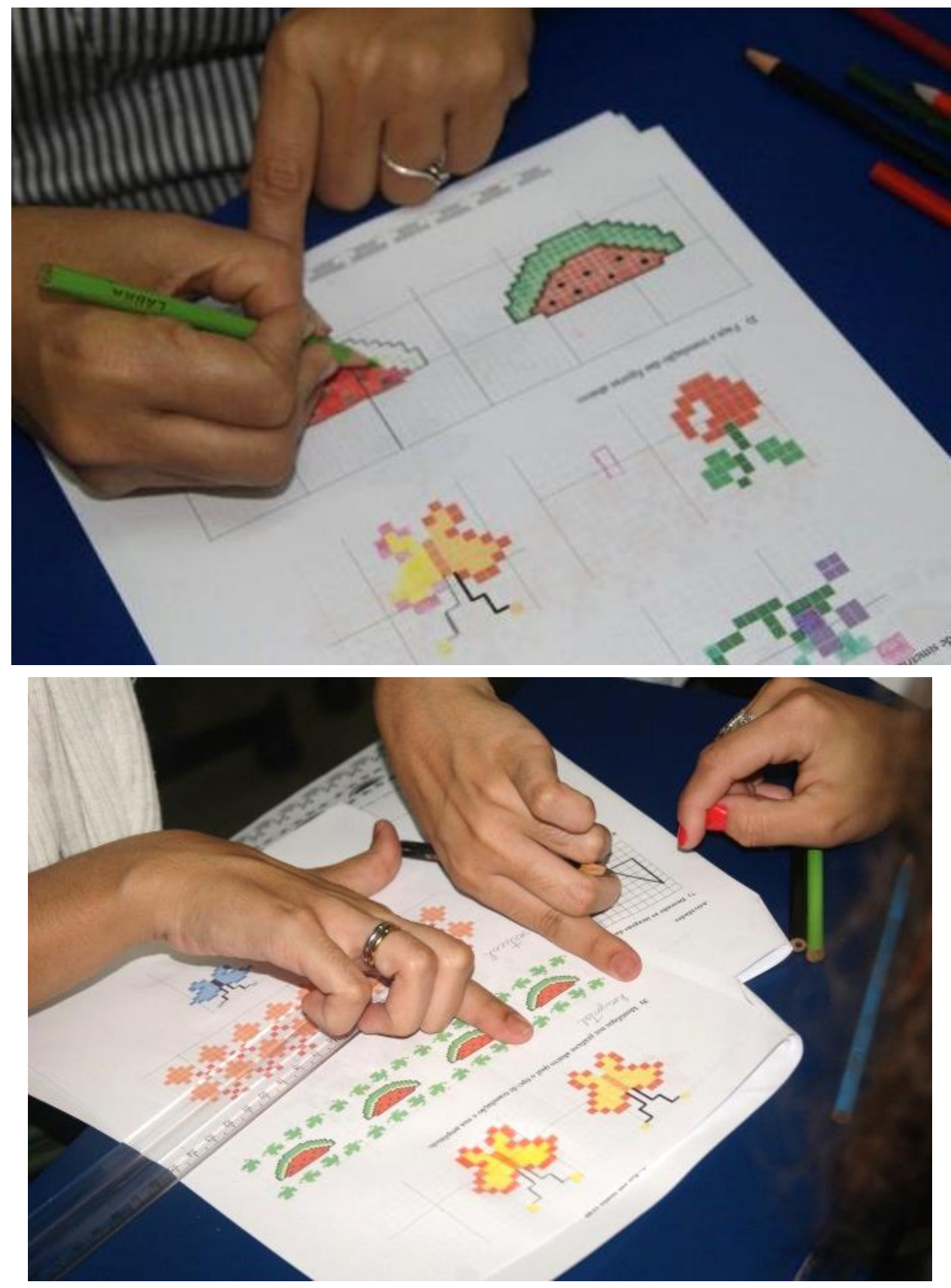

Fonte: Dados de pesquisa.

As barras de étamine utilizadas nas oficinas já estavam iniciadas com algumas atividades devido o pouco tempo e visando agilizar o trabalho. A seguir, apresentamos duas figuras que mostram a barra já iniciada e como ela fica após as transformações aplicadas (fig. 5). O coração é para ser realizada uma rotação de 90o, transformando-o em uma pétala da flor, já o ramo de flores deveria ser refletido a partir de um eixo de simetria horizontal. O arco íris está incompleto, considerando que o corte se deu no seu eixo de simetria o participante deveria completar a figura construindo 
uma imagem simétrica. Por fim, a imagem da maçã deveria ser transladada por um vetor qualquer de acordo com a escolha do participante.

Figura 5 - Modelos da étamine com as atividades: inicial e finalizada.
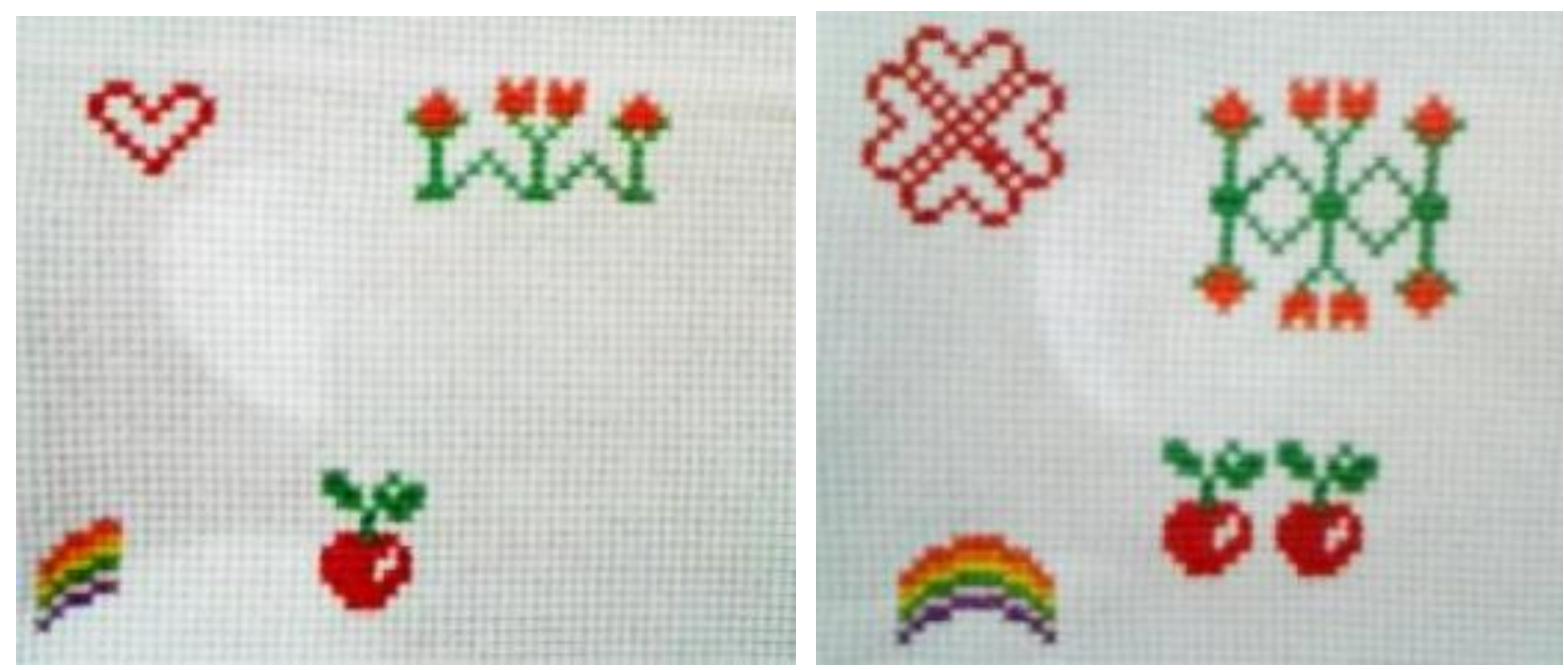

Fonte: Dados de pesquisa.

Figura 6 - Aluna bordando a atividade e modelo de rotação na étamine.
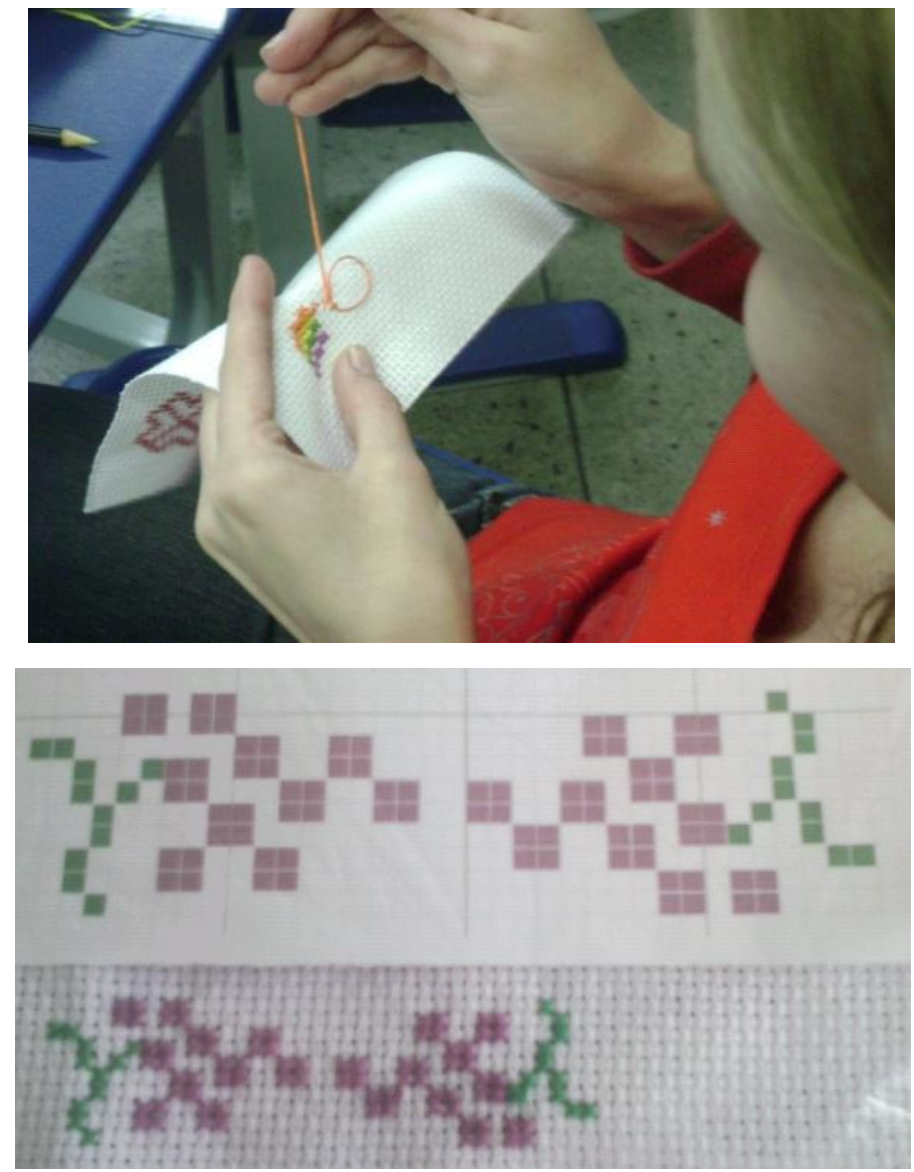

Fonte: Dados de pesquisa. 
Percebemos que todos os participantes, os que tinham alguma noção de bordado em ponto cruz e sabiam fazer essa arte e também aqueles que nunca tinham realizado esse tipo de artesanato conseguiram desenvolver as atividades sem maiores dificuldades. Tivemos em algumas oficinas com a presença de homens e eles também não tiveram problemas em realizar os bordados. As pessoas ficavam apreensivas em como iriam desenvolver a atividade com artesanato, visto que, alguns afirmavam que não tinham paciência e nem habilidade para esse tipo de tarefa. Incentivamos os participantes a tentarem e colaboramos mais com os que não sabiam ou tinham dificuldades. Notamos que essas atividades contribuíram para a percepção e a visualização das transformações com algo real (BRASIL, 1997).

Ao longo das oficinas realizávamos discussões sobre os temas abordados e notamos que os participantes se envolviam nos debates e a construção de conceitos geométricos acontecia a partir dessas inferências dos participantes junto às pesquisadoras. Em cada oficina realizamos avaliação oral e escrita do processo de aprendizagem e da oficina em si junto aos participantes. Baseamos em respostas desses participantes para avaliarmos a proposta e validarmos nossa intenção de levar para a sala de aula essa abordagem.

O questionário realizado ao término das oficinas solicitava que os participantes escrevessem os pontos positivos e negativos da mesma. Pedimos que nenhum participante se identificasse. Apresentamos algumas respostas sobre os pontos positivos da oficina e nossa análise sobre o que foi escrito.

A proposta de trabalho relativamente simples possibilita a abordagem $e$ desenvolvimento de conhecimentos, conceitos, aplicação $e$ habilidades motora e posicional. Além das habilidades artísticas, estéticas e visuais (participante 1).

Achei a oficina bem interessante uma vez que eu não tinha um desempenho legal nas transformações geométricas, reflexão, translação e rotação e fazendo tudo isso com o ponto cruz foi algo inovador e bem legal. Assim, fazendo na prática tive ideia do certo $e$ errado, melhor para visualização (participante 2). 
Notamos que tanto na fala da participante 1 como a participante 2 percebemos a importância de utilizar materiais manipulativos e do mundo real para uma aproximação com conceitos matemáticos. Veloso (2000, p. 50) afirma que "a matemática, quando interpreta uma certa realidade, por exemplo as figuras da arte decorativa produzida desde há milhares de anos por povos de todo o mundo, procura encontrar regularidades que conduzam a processo de classificação e organização de objetos dessa realidade". Portanto, analisar ponto cruz e as isometrias presentes nessa arte contribui para a prática, a vivência das pessoas que participaram das oficinas. Essas participantes indicam ainda que estamos contribuindo para o fazer artístico, que aposta na imaginação da pessoa (SANTOS; TELES, 2011).

É uma oficina interessantíssima que pode contribuir muito para o ensino da geometria no ensino básico. Essa oficina me fez refletir e pensar em novas ideias. É também uma oficina de inclusão, permite que os alunos tenham um trabalho de artesanato (participante 3).

Os comentários acima confirmam que os participantes compreenderam o objetivo da oficina de evidenciar as transformações geométricas de forma atrativa e diferenciada. Iniciando o estudo das isometrias pela intuição e por investigação dos bordados de ponto cruz (NASSER; TINOCO, 2004; VELOSO, 2000). Notamos ainda que favoreceu o desenvolvimento do pensamento geométrico partindo de situações concretas e que estão presentes na nossa cultura brasileira.

Os pontos negativos evidenciados pela maioria dos participantes foram o pouco tempo, como podemos ler a seguir, o que vidência que as oficinas são disparadores de ideias, sabíamos que o tempo seria insuficiente para uma abordagem mais ampla e detalhada das isometrias. Porém, nosso objetivo era iniciar pela intuição construção de pensamento geométrico relacionado as transformações geométricas.

O único ponto negativo pra mim foi o pouco tempo que durante a oficina passou muito rápido (participante 4). 
Também buscamos aplicar oficinas com os alunos jovens e adultos da educação técnica profissional do Ifes. Marcamos encontros semanais, todas as terças-feiras durante o mês de maio de $09 \mathrm{~h} 30 \mathrm{~min}$ as $11 \mathrm{~h} 30 \mathrm{~min}$, com os alunos que manifestaram interesse em participar da pesquisa, porém apenas uma aluna compareceu aos primeiros encontros marcados e nos próximos encontros desistiu de participar por problemas de estar na instituição no contraturno que fazia o técnico. Durante participação dessa única aluna nos primeiros encontros, ela dizia gostar de bordar e achava muito interessante unir o ensino de matemática com os bordados em ponto cruz, conforme comprovado no relato a seguir.

Aprender matemática com algo prático, com coisas do cotidiano é essencial para vida. Nunca relacionei a matemática com o bordado em ponto cruz, percebo que agora é possível aprender matemática. Tem hora que dá um nó na minha cabeça, mas estou gostando! (aluna do PROEJA)

Diante dos expostos acima, fica evidenciado que a utilização dos bordados em ponto cruz no estudo das transformações geométricas facilita a visualização das propriedades e dos conceitos envolvidos. Além de promover o desenvolvimento do senso crítico e do espírito investigador, que ajuda na compreensão e entendimento de determinados tópicos relacionados ao ensino da matemática.

\section{CONSIDERAÇÕES FINAIS}

Neste trabalho, apresentamos parte de um estudo sobre transformações geométricas no plano, em especial as isometrias, por meio de bordados em ponto cruz. Essa pesquisa representa uma possibilidade de transformar a geometria em uma matéria mais acessível e relacionada ao cotidiano, em especial efetuando uma ligação entre a geometria e a arte. Observamos em Oliveira e Silva (2012), que a união da matemática e a arte auxiliam no pensamento crítico, na autonomia intelectual, na sensibilidade e na criatividade.

Concordamos com Catunda (1988, p. 11) quando diz que "o ensino da geometria não se renovou e, com isso, ela perdeu seu vigor" e com esse trabalho buscamos novas possibilidades para o ensino 
da geometria e acreditamos que explorar as transformações geométricas por meio dos bordados em ponto cruz é um caminho para abordar os conceitos geométricos de forma dinâmica e interessante. Além de aliar a matemática com a arte o que permite desenvolver habilidades como percepção visual e geométrica, sensibilidade e criatividade. Os participantes aprovaram a maneira de abordar as isometrias, partindo da investigação, mas sabemos que precisamos de um tempo maior e com uma investigação mais detalhada para conseguirmos aprofundar e avançar para a abstração que vai além da ideia intuitiva inicial que abordamos (VELOSO, 2000; 2012).

Abordamos as transformações geométricas, que normalmente não são trabalhados em sala de aula, por meio de bordados em ponto cruz visando facilitar a construção de conceitos geométricos e auxiliar na visualização e na percepção desse conhecimento. Identificamos que existem diferentes possibilidades e que os participantes gostaram da ideia e se envolveram na resolução das atividades e na produção dos bordados em ponto cruz mesmo com a falta de confiança inicial por desconhecerem e afirmarem não ter habilidade nesse tipo de artesanato.

Notamos que precisamos ajudar aos professores e futuros professores a visualizarem outras opções de atividades para trabalhar geometria e que em algumas situações podemos utilizar situações e atividades do cotidiano para desenvolver conceitos matemáticos. Uma das causas evidenciadas por Catunda (1988) pela falta de compreensão dos conceitos geométricos pelos alunos do ensino fundamental é que os professores não dominam conhecimentos da geometria, influenciados pela geometria que eles tiveram e por isso a excluem de seus planos de aula. Por esse motivo ressaltamos a necessidade de aprofundamento dessa abordagem em formações iniciais e continuadas com uso de diferentes materiais e atividades didáticas, de modo a aprofundar as ideias iniciais e chegar a abstrações e generalizações.

Nas oficinas realizadas os participantes ficaram fascinados com as possibilidades que o ponto cruz apresenta para o estudo de conceitos geométricos. Além de proporcionar aos participantes um aprendizado diferenciado sobre transformações geométricas aliando à matemática a arte mostrando que a geometria pode ser ensinada e aprendida de forma dinâmica com ênfase em atividades do mundo real, nesse caso os bordados em ponto cruz. Defendemos que essa abertura para um novo olhar sobre os bordados e a ampliação da ligação entre a matemática e a arte pode 
suscitar alternativas de investigações e análises que podem favorecer o aprendizado da geometria na educação básica.

\section{REFERÊNCIAS}

BISOGNIN, Eleni; ROSSI, Gicele da Rocha. Explorando as transformações geométricas por meio da arte. Publicado nos Anais do X Encontro Gaúcho de Educação Matemática, ljuí, Brasil, jun 2009.

BRASIL, Secretaria de Educação Fundamental. Parâmetros Curriculares Nacionais: Artes. Brasília: $\mathrm{MEC} / \mathrm{SEF}, 1997$.

, Secretaria de Educação Fundamental. Parâmetros Curriculares Nacionais: Matemática. Brasília: MEC/SEF, 1998.

, Secretaria de Educação Fundamental. Guia do Livro Didático: PNLD 2010: Alfabetização Matemática e Matemática. Brasília: MEC/SEF, 2009.

CATUNDA, Omar et al. As transformações geométricas e o ensino de geometria. Salvador: Centro Editorial e Didático da UFBA, 1988.

FAINGUELERNT, Estela Kaufman; NUNES, Kátia Regia Ashton. Fazendo Arte com a Matemática. Porto Alegre: Artmed, 2006.

NASSER, Lilian; TINOCO, Lucia. Curso Básico de Geometria: enfoque didático. Módulo II Visão dinâmica da congruência de figuras. Rio de Janeiro: UFRJ/IM. Projeto Fundão, 2004.

OLIVEIRA, Sabrine Costa; SILVA, Sandra Aparecida Fraga da. Reflexão e Translação em bordados de ponto cruz. Anais do 3 Simpósio Internacional de Pesquisa em Educação Matemática, Fortaleza CE, jun 2012.

SANTOS, L.F.; TELES, R.A. de M. Pintando e borrando: o encontro da simetria com as artes visuais. Publicado nos Anais do XII Conferência Interamericana de Educação Matemática, Recife - PE, jun 2011.

VELOSO, Eduardo. Geometria: temas atuais. Materiais para professores. Lisboa: Instituto de Inovação Educacional, 2000.

VELOSO, Eduardo. Simetria e transformações geométricas. Textos de geometria para professores: Grupo de trabalho de geometria. Lisboa: APM, 2012. 